\title{
Ethical Wisdom and Philosophical Judgment in Amish Tripathi's The Oath of Vayuputras
}

\author{
Lata Mishra \\ Department of English Government KRG Autonomous PG Girls' College Gwalior, Madhya Pradesh \\ *Corresponding Author: dr.lata.mishra@gmail.com
}

Copyright (C) 2013 Horizon Research Publishing All rights reserved.

\begin{abstract}
This paper considers 'culture' as a framework in which people live their lives and communicate shared meanings with each other. Culture has been a dynamic system through which a society constructs, represents, enacts and understands itself. The research documents the way human consciousness cognizes and registers the world around her/him. "The Shiva Trilogy" authored by Amish Tripathi combines the narrative excess with philosophical debate. The fiction depicts that the culture evolves as men sacrifice their duty (swadharma) for the greater good, Universal Dharma. The Oath of Vayuputras, enlivens consciousness and promotes the experience of a new sense of Self. It contends that the engagement of self in action, purifies man. Knowledge liberates an individual. While the study discusses the issues of liberation, emancipation, equal rights and womanhood, it gives significance to humans and their relations, as self does not exist in seclusion. While enriching the differences, this fiction strengthens the cultural integrity of India. Through recreation, "The Shiva Trilogy" becomes the living inspirational scripture capable of providing spiritual direction to the present world.
\end{abstract}

Keywords India, Myth, Culture, Shiva Purana, Dharma

\section{Introduction}

We as individuals and societies are all so different, yet at the same time so similar. English Anthropologist Edward B. Tylor in 1871 said that culture is "that complex whole which includes knowledge, belief, art, law, morals, custom, and any other capabilities and habits acquired by man as a member of society [1]. This paper will discuss that the culture of nations is governed by Laws of Nature which structure and administer people and nations. All the elements of the life and their inter-relationships leading to evolution are ruled by Natural Law. Amish Tripathi, a young debutante novelist of India rewrites Shiva Purana, a sacred Hindu text as a novel with two sequels. While the first novel, The Immortals of Meluha, introduces the readers to ancient Indian culture, the second one, The Secret of Nagas philosophizes the concept of good and evil, as perceived in Indian society. The concluding novel, The Oath of Vayuputras, argues and to a great extent convinces that the culture of the nation, that ignores the Laws of Nature, violates it, while the one that follows Laws of Nature leads its nation towards enlightenment. For fulfilling, harmonious and progressive life one is required to live in accordance with Laws of Nature or Dharma. The trilogy combines the narrative excess with philosophical debate.

Amish recreates the myth of Shiva, Ganesh, Sati and Kali through his study of all spheres of Indian life and literature. He makes Shiva myth appealing and intelligible to the modern mind. Those who still keep the oral tradition alive through chanting and singing of hymns and folk songs deserve gratitude and admiration of young generation. At the same time, there is also a need to understand and reinterpret its meaning. Recitation without a knowledge of its meaning does not enlighten one. Amish insists to engage oneself in action because actions purify as knowledge liberates. Through recreation, 'The Shiva Trilogy" becomes living inspirational scripture capable of providing spiritual direction in the modern world. This paper considers 'culture' as a framework in which people live their lives and communicate shared meanings with each other. Culture has been a dynamic system through which a society constructs, represents, enacts and understands itself. Humans differ from each other as they are exposed to different lives in different cultures. Cultures are built up in period of centuries, yet they survive on the successful transmission of values, ideas, history and beliefs from one generation to the next. At the same time culture also promotes evolution. It leads nation towards higher state of Consciousness.

As Indian philosophy perceives, Amish too presents individual psyche and society as a system that undergoes the process of self-creation and self-generation as opposed to a deliberate construction. As amply explicated in the paper, the society is in constant interaction with its surroundings and any attempt to block the system would be to cut it off from the interactions that maintain it, thereby likely leading to its destruction. It is also assumed that chaos theory may help in understanding God's creating and ordering of this universe. Present paper is an attempt to explore identity, reality, 
knowledge and the dichotomy of the order/chaos axis in context of a universal understanding of consciousness.

Laws of Lord Ram in this fictionalized account govern the geographic and climatic conditions of Indian society at family as well as individual level. The different properties of rivers, rocks, forests, temperatures influenced the cultural life of Meluhans. The river Jhelum that roars on the mountains slows down in Meluha, a Suryavanshi kingdom, bestowing nature's loving care on the people of this land. Gunas and Prakrits (the two rival tribes in Tibet) have to stand against the brutalities of roaring water and cold harsh winds of mountains. Prakrits and Gunas live in unkind nature and thus always aggressively engage in war to extract the limited benevolences of Mother Nature. River Saraswati flows through Meluha and facilitates the preparation of Somras. The poisonous by-products produced in the process are released into a lesser river in Himalayas thus forcing consumption of toxic waters by Brangas. Longevity and good health of Meluhans comes at the price of deaths and diseases of Brangas. Even Suryavanshis are not untouched by the side effects of excessive use of Somras. Deformed children and their parents live on fringes of the society. Brangas and Nagas share the negative effects of Meluhan life and hence deviate greatly from the Meluhan culture. Swadweepans, a Chandravanshi kingdom, deprived of the geographic and climatic advantages of Meluhan life created difference in their mannerisms, traditions and behaviours. Since they receive limited supply of Saraswati waters so only royalty is benefitted by Somras. The overpopulated Ayodhyans live chaotic life and have compromised with Laws of Ram on various grounds. Vayuputras and Parihans lived holistic life and remained unpolluted in isolated lands where, with their efforts, they have created their own world unreachable by others. Thus the climatic and the geographical factors shape the physiology and psychology of the individual and the society of the region.

\section{Methodology}

The Immortals of Meluha opens with Shiva's childhood and a dream that decides his course of action in future. This section of the novel that deals with the childhood memory and consequent dreams of Shiva is examined under the lens of Carl Jung's On the Nature of Dreams (1967). The brief introduction of the selected novels is followed by the study of the various Vasudevas, Shiva meets on his transformative journey to the kingdoms/cities in the novels. Vasudevas initiate and direct Shiva in his karma. There are almost twelve discourses with them. Vasudevas are presented as scientists who live in temples which serve as transmitters from where they communicate with each other through radio waves. Their conversation with Shiva is analysed in light of different theories in Physics, namely, Newtonian Absolutism, Einstein's Relativity, Heisenberg's Indeterminacy. The various cities and kingdoms exist as organic entities in the narrative. These cities can thrive and grow, but they also age and decline, as if they have the life of their own. The three novels are thus, also explored through the application of the nonlinear dynamics theory and the discussion on the chaotic attractors of dynamical systems. The complexity theorists view all systems as self-organizing.

\section{Results}

Young Shiva's dream fetches out unconscious contents that have so far been suppressed by his consciousness to the surface. Discourses held with Vasudevas in the various temples inspire Shiva to evolve through continuous development of consciousness to become a universal human being. He cognizes and represents universal mechanics of creation and lives higher states of consciousness. In society, clashes/chaos may occur, resulting in fall from equilibrium, but, the dynamics can bring the society towards a new emergent structure. Besides this, the paper more importantly exposes and explores the patterns within a social system, which, in turn, may give a greater understanding of the system. The novels under study, seem to suggest a need to perceive, the interactions occurring within a structure, on the basis of which, reframing and consequently, progress may take place. Society is a living entity and thus it is also realized that it self-creates and self-constructs itself.

\section{Discussion}

\section{Section 1.1}

Shiva, a youth from Tibet begins his journey from Mt. Kailash in Tibet to Meluha and Swadeep. Shiva then marches to Brangaridai and Dandak Forests near Narmada. Shiva moves to Meluha on beckoning of Nandi, the Meluhan captain. Meluha is a vast empire in North India extending from Kashmir to Gujarat, Rajasthan and parts of Uttar Pradesh. Here he meets Sati, the daughter of Daksha, the emperor, and falls in love. When Sati explains him why she would not attend yagna, a ceremonial fire sacrifice organized by the royal party, Shiva's mind revolts at the humiliation of his beloved and the injustice done to vikarmas (socially ostracized group) in Meluha. Shiva is desperate to bring dignity back to his beloved and the dream of the childhood traumatic event is back that night. Vikarmas are the subjugated group in Meluha. This system of labeling of Vikarma is not based on caste but as Nandi, the captain in Meluha Kingdom explains:

Vikarma people, my Lord are people who have been punished in this birth for the sins of their previous birth. Hence they have to live this life out with dignity and tolerate their present sufferings with grace. ... They are not allowed to marry since they may poison others with their 
bad fate. They are not allowed to touch any person who are is not related to them or is not part of their normal duties ${ }^{1}$.

Sati, the princess is one of the vikarmas, but is privileged to live in a palace. She strictly adheres to all other rules laid down for vikarmas. Any person who touches a vikarma has to observe Shudhikaran ritual. Childhood memories reside in the conscious and unconscious mind. An individual suppresses traumatic memories unconsciously and these memories are "repressed memories." Such memories are the ones suppressed beyond the realm of conscious awareness.Repressed memories are often, the stuff that contains unbearable pain, fear or disgust, experienced by an individual. Shiva as a young child has suffered such an experience when one day while returning home in dusk at his native place, Mt. Kailash, he falls upon a man and woman caught in an act. Initially the young boy is excited to watch and later report to his teenage friends but suddenly he realizes that it's a sexual assault by the man. As the victim woman notices him and cries for help, scared Shiva flees from the spot, never turning back.

\section{And then came the moment that would haunt him for the rest of his life...The hairy monster turned to see who the woman was calling...The boy quickly picked up his sword and fled... He could hear the man's heavy breathing ${ }^{2}$.}

Carl Jung,a Swiss psychiatrist and the founder of analytical psychology regarded the nature of dreams to be "a spontaneous self-portrayal, in symbolic form, of the actual situation in the unconscious" [2]. Our unconscious mind in our dreams expresses itself in a language of symbols, images, and metaphors. Shiva's suppressed memories of this incident diminishes his personal value and makes him feel bad about himself. Repression is an unconscious act while suppression is conscious effort. However hard Shiva tries, he finds forgetting difficult. For this he often resorts to Marijuana. Jung suggests two functions of dreams. Dreams compensate for imbalances in the dreamer's psyche. They bring unconscious contents that have so far being suppressed by consciousness to the surface. Shiva's dream of the same woman calling for help keeps recurring in the novel. He wishes to 'redeem' himself.

According to Jung, when the dreamer recognizes and accepts the unconscious contents in his psyche, greater psychological balance is achieved. Jung further argued that dreams unite consciousness and the unconscious in a healthy, harmonious state of wholeness. He termed, this process as individuation, which is the "complete actualization of the whole human being" [3]. Amish's aim in this meta-narrative seems to provide practical knowledge of

1 Tripathi, Amish. The Immortals of Meluha.(2010) p.93

2 Tripathi, Amish. The Immortals of Meluha.(2010) p.221. consciousness, this knowledge is boundless, infinite field of wakefulness that can be explained by an individual as his/her own simplest form of awareness. The other terms Jung uses for consciousness is ego or persona. Persona is the mask that one wears in society to adapt to its norms. Beneath the persona lies shadow that is all that is repressed. A self-conscious person confronts with his shadow and the world of darkness. Shadow often surfaces in our dreams and is of the same gender. Shiva's dream remains the same with minor deviances. Acting upon a thought, in waking state of consciousness, one is bound to a cycle of experience, impression, desire, action and further experience. The childhood experience leaves impression on the mind of Shiva. Whenever in adulthood the new impressions associate themselves with similar past experience stored in Shiva's mind an impulse is created that rises to the thinking level and assumes a form of thought. Through this thought a desire emerges and in turn Shiva spurs into action.

\section{Section 1.2}

According to Bhagwat Gita a man cannot live without action, even for a moment. The Immortals of Meluha, depicts Shiva, an adolescent boy feels guilty of not saving a woman from being sexually assaulted by a monster. This childhood event keeps torturing him in his dreams. Life is a relationship and to be related is to act. Shiva's act of thoughtlessly jumping into the situation would have been only reaction in the given circumstances and not action, in true sense. A reaction emanates from a fixed center in one's consciousness. It may be propelled by a habit or memory. An action precede thought. at the said moment Shiva does not react but his mind has acted upon even before thought. His action is the most pure one. His action of looking at the miserable woman precedes any thought and so is true looking. The experience remains etched in his mind throughout his life. True relationship with this unnamed and unknown woman is established for rest of his life. The experience jolts him from within. Had he fought with the man and got killed, the action would have remained incomplete and such incomplete actions are verily reactions which would have begotten frustrations and anxieties. This action stimulates and inspires Shiva, the boy to grow up to be Mahadev (the great God). He accepts the invitation of Nandi and fights with Sati against the Naga to save her.

Nagas are introduced as evil force in Book 1 by Nandi as:

They are cursed people, my Lord,.. are born with hideous deformities because of the sins of their previous births. Deformities like extra hands or horribly misshapen faces. But they have tremendous strength and skills. The Naga name alone strikes terror in any citizen's heart. They are not even allowed to live in the Sapt Sindhu,'... 
Our land, my Lord, the land of seven rivers. The land of Indus, Saraswati, Yamuna, Ganga, Saryu, Brahmaputra and Narmada. This is where Lord Manu mandated that all of us, Suryavanshis and Chandravanshis, live ${ }^{3}$.

These Nagas, who are dreaded terrorists in Meluha and as reported, have allied with Chandravanshis, in Book-I, readers come to know in Book II, have settlements in Panchavati. Naga people parade the city once a week singing songs that reflect their emotions:

$$
\begin{gathered}
\text { You were my world, } \\
\text { my God, my } \\
\text { creator, } \\
\text { And yet, you } \\
\text { abandoned me. } \\
\text { I didn't seek you, } \\
\text { you called me, } \\
\text { And yet, you } \\
\text { abandoned me. } \\
\text { I honoured you, } \\
\text { lived by your rules, } \\
\text { coloured myself in } \\
\text { your colours, } \\
\text { And yet, you } \\
\text { abandoned me. } \\
\text { You hurt me, you } \\
\text { deserted me, you } \\
\text { failed in your } \\
\text { duties, } \\
\text { And yet, I'm the } \\
\text { monster } \\
\text { can I.... }
\end{gathered}
$$

As a man Shiva brings social reformation in totalitarian society of Meluha. His fulfilling harmonious and progressive life is lived in accordance with Dharma. He marries widowed Sati, accepts Ganesh, born out of her first marriage, as his son. He promotes evolution that leads nation towards higher state of consciousness. This makes him an enlightened human being, Neelkanth. People of Meluha, Swadeep, Branga and Naga become his followers. These men sacrifice their duty (swadharma) for the greater good, Universal Dharma. Universal cultural views that Shiva

3 Tripathi, Amish. The Immortals of Meluha. (2010) p.59.

4 Tripathi, Amish. The Secret of the Nagas.(2011) p. 147 stands for, is beyond social determinism. Having completed his Karma Pashupati returns to his place of origin. Years later Shiva still dreams of the helpless woman.

Shiva woke up sweating, his heart pounding madly. He instinctively turned around, wanting desperately to go back to that dreadful day. to redeem himself. But there would be no redemption. the woman's terrifying face came flooding back ${ }^{5}$.

\section{Section 1.3}

Realizing the futility of constant battles with Prakrits, Shiva decides to migrate to Meluha and provide his clan, Gunas with better living. In his action lies his sacrifice of being the leader of his clan, as in the new land his status would be of any migrant. Brahma having created his universe does not interfere in its activities. He gives each individual opportunity to unleash his tremendous potentialities lying concealed in his nature. The role of man is never derided upon. Initiatives on the part of man are, in fact, encouraged by the creator. Shiva, a mortal man realizes his duties and acts upon them with full devotion. Human societies as they grow pass through numerous errors and mistakes. They may be lured by their own discoveries (Somras) and hence corrupt themselves. But thus alone can they grow and come to real maturity. In the process of stumbling man learns to evolve from Instinct to Intellect. The instinct to make oneself immortal is natural, pure and innocent. As intellect (Brahmnayak) works towards it, man (Daksha) becomes vile and corrupt, but this should not be regarded as an interlude as in the evolutionary process, intuition dawns upon mankind and Dharma wins. Shiva's action with Sati, masculine and feminine aspects of consciousness succeeds in making of a new world where man can rise to his spiritual status.

Though in the mythology, Shiva distraught in pain ignores his divine duty and almost destabilizes the world, in this modern retelling of Shiva myth, Neelkanth restores the stability of the subcontinent by engaging in the war and using Pashupatiastra. After performing cremation of his brave wife, Shiva, the lover holds back a portion of her ashes, which later Kali persuades him to consecrate at fifty one places (recognized now as pithas) across India. In this way India becomes a sacred land by Sati's ashes. Indian Philosophy believes in the position of knowledge (buddih) over the five sense organs, but above this comes the Soul (ksetrajnah). Shiva feels pleasure and pain in the knowledge and realizes that though the soul is bound by knowledge, yet is not entangled in pleasure and grief. Hence the Deliverance comes with the recognition that these feelings belong to earthly nature. Shiva's soul thus finds the highest nature.

5 Tripathi, Amish. The Immortals of Meluha.(2010) p.222. 
Shiva retires to the remotest location of Kailash for isolated meditation and can be contacted through Nandi only and hence the legend.

\section{Section 2.1}

Vasudevas in the novels serve as stimulants to Shiva. The rise of self-consciousness in Shiva may be traced in his relation with all the vasudevas in the two novels. The first Vasudeva, Shiva meets is in Brahma Temple at Meru. Shiva meets Sati and falls in love at this place. This Vasudeva reappears in Shiva's dream. In the chapter "Attack on Mandar," Amish brings in the Derridean play between "presence" and "absence" and concomitantly dissolves their difference. The first Vasudev of Brahma Temple convinces Shiva that the existence (presence) of the world is actually constructed around its absence. In other words, it is the absence that constructs the presence and the existence of "presence" is impossible without the conception of its "absence." The Pandit engages Shiva in a dialogue and fittingly argues:

"What is the colour of that leaf?...It's green."...... Light falls on that an object and when it reflects back from that, you see that object.... What normal sunlight is made of?... White light is nothing but the confluence of seven different colours...White sunlight falls on that leaf. The leaf's physical properties are such that it absorbs the colours, violet, indigo, blue, yellow, orange and red... It doesn't absorb the colour green, which is then reflected back, Hence I see the leaf as green... What colour it absorbs and what it rejects. Or is it every single colour in the world, except green?" 6

Martin Heidegger, rejects calculative, utilitarian view of reason. To him reason is not the sole source of legitimate. The knowledge of truth cannot be confined to rationalized propositions about beings alone but ought to encompass the knowledge of the Being of beings. Rational and scientific knowledge just give the information from one particular perspective. Therefore any one kind of knowledge of beings cannot be privileged over any other. No propositional knowledge is absolute; it is all relative. Vasudeva continues his discussion:

There are many realities. There are many versions of what may appear obvious,' ... 'Whatever appears as the unshakeable truth, the exact opposite may also be true in another context. It is the context or perspective that you're looking from that moulds which particular reality you see. ${ }^{7}$

In their interaction both the Vasudeva and Shiva rise to self-consciousness. Vasudevas are informative, but Shiva is investigative. He sees things external to him. In an attempt to know them he works on them and shapes them. His interactions with Kali, Ganesh, Parashuram and societies of Meluhans and Swadeepans, in general, enables him to inwardise them. In his way he gains self-consciousness. Indian philosophy believes that at birth, an individual's mind contains past impressions (karmasaya). These impressions combined with hereditary constitution and social influences develop the psyche of an individual. Vasudevas in the novels address Shiva as 'fellow traveller in karma, karmasarthi' ${ }^{8}$

\section{Section 2.2}

Jacques Derrida's introduction of the notion,Différance suggests that without differentiation there could be no experience, meaning or being. Following this, the search for absolute truth or singular vision of self and the world seems a fancy idea. Taking this further, the absolute must rest upon the foundation of that which is different from itself. This argument leads to a respect for differences and rejection of Hegelian-like attempt to integrate all ideas. The ideas thus are integrally related to their polar opposites. The one cannot be treated as superior to the other. Jung echoes similar ideas but takes a step forward:

“...he who accepts what approaches him
because it is also in him, quarrels and
wrangles no more, but looks into himself
and keeps silent. He sees the tree of life,
whose roots reach into Hell and whose
top touches Heaven. He also no longer
knows differences" [4]

Amish, in accordance to Indian philosophy re-enlivens the universal field of pure consciousness. Reconciling or holding together of opposite values is the fundamental property of consciousness. This theme of opposites co-existing the universe surfaces repeatedly in the conversation of Vasudevas. The second Vasudeva, Shiva meets is at Mohan Temple of Mohan Jo Daro at Meluha. Knowledge proper is obtained by ordering, connecting and synthesizing the Shiva-Vasudeva meetings into some system. The discourses held in these meetings leaves readers with the hope to achieve infinite creativity and fulfillment. Shiva evolves through continuous development of consciousness to become a universal human being. He cognizes and

7 Tripathi, Amish. The Immortals of Meluha.(2010) p.296.

8 Tripathi, Amish. The Immortals of Meluha.(2010) p.46. 
represents universal mechanics of creation and lives higher states of consciousness.

Shiva meets the third Vasudeva in Ayodhya at Ram Janambhoomi. Shiva fights war against Chandravanshi on being convinced by Meluhan emperor of their being evil. Later in despondent and remorseful mood he ponders over the war and defeat of chandravanshis, whom till now he had thought to be evil. The Vasudeva enlightens Shiva that universe is a manifestation of the illusion of duality. The dynamics of existence of the masculine and feminine principles is the most fundamental concept in life consciousness. He says,

Yes, a duality that is one of the many perspectives of the universe-the masculine and the feminine. The Asuras and the Suryavanshis stand for the masculine. The Devas and the Chandravanshis speak for the feminine. The names change, but the life forces they embody remain the same. They will always exist. There is no way that either can be destroyed. Otherwise the universe will implode ${ }^{9}$.

\section{Section 2.3}

The Vasudeva of Magadh Temple gives Shiva insight into the masculine and feminine principle operating in the universe. Meluhan order in the novel is perceived as masculine attitude, that reflects the authoritative, vertical, hierarchical order of being and knowledge, while Swadeepan chaos as Feminine attitude that contains the seeds of order within. While the conversation with the mundane characters remains at the expressed level of speech, the discourse with Vasudevas is carried out at subtle and Transcendental level of pure consciousness, without sounds. Their minds send radiowaves to each other and thus eliminating the possibility of gap between sound and meaning. Vasudeva of Ayodhya temple urges Shiva to let his thoughts flow freely in order to discover the truth. Vasudeva of Magadh Temple explains

Everything needs balance, Neelkanth. The masculine needs the feminine. The energy requires the mass $^{10}$.

Vasudeva's words may be examined under Bohr's principle of complementarity. According to him every entity in Nature posses pairs of contradictory characters such as corpuscular property and wave property. The contradictory characters are not exclusive of each other, but are complementary. For an integral comprehension of the entity as a whole, it is necessary to know both the contradictory

9 Tripathi, Amish. The Immortals of Meluha.(2010) p.392. 10 Tripathi, Amish. The Secret of the Nagas.(2011) p.113. characters. At Kashi Vishwanath Temple Shiva gains insight into:

There is a god in every single one of us. And there is evil in every single of us. The true battle between good and evil is fought within.

And the great evil connects itself to the evil within s $^{11 .}$

Vasudev Pandit, Gopal of this temple says:

Lord Manu had said it's not people who are evil. True Evil exists beyond them. It attracts people. It causes confusion amongst its enemies. But Evil in itself is too big to be confined to just a few.

Shiva frowned. You make it sound like Evil is a power as strong as Good. That it doesn't work by itself, but uses people as

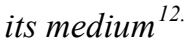

So why does Evil exist? Why can't it be destroyed once and for all?...but Evil does rise and will keep rising again and again Why?...Because Evil serves a purpose...

That is what Lord Manu believed. And the institution of Mahadev acts as the balance, the control for that purpose. To take Evil out of the equation at the correct time ${ }^{13}$.

\section{Section 2.4}

Plurality of truths contained in scriptures formed by blend of history, folklore and empirical knowledge is limited by finiteness of human mind as well as culture of the time. Amish Tripathi delves deep into this great Shiva myth of India and employs it as a vehicle of a new vision and interpretation. There is order in creation, and system in nature. Shiva gains Knowledge of Supreme Creativity, that can hold universe in one wholeness. The initial order of the world that gets derailed in course of time, creating chaos is restructured and aligned with the cosmic structure by Shiva, bringing a new evolved order into existence. Thus the cyclity continues. For the non-dualist philosophers, the pure-consciousness exists below the surface of all the micro-entities of the phenomenal world. It is this Reality that Shiva, the man strives to achieve through his karma and

11 Tripathi, Amish. The Secret of the Nagas.(2011) p.114.

12 Tripathi, Amish. The Secret of the Nagas.(2011) p.276

13 Tripathi, Amish. The Secret of the Nagas.(2011) p.277 
perseverance. Universal cultural value is pure self-referral consciousness and is remains uninfluenced by individual cultures: Meluhan, Swadeepan or any other. Universal cultural value that Shiva stands for is beyond social determinism. It is the source of individual mind. The basic idea about action in the novel is that man as a conscious being, brings about some change within himself or in his world with a given purpose, under certain circumstances. After Shiva's victory and destruction of Somras factory, river Ganga that carries soul of pure Saraswati, meets Yamuna and reaches Brangas who worship it as their mother. Their land is now as habitable. Hindu mythology credits heroic austerities of Bhagiratha for bringing Ganga on the earth. The novelist admires Bhagiratha, the son of Dilipa and prince of Ayodhaya for his unflinching faith in Shiva and active participation in the Dharamyudhh.

\section{Section 3.1}

To analyse the Shiva-Vasudeva conversation carried out with the second Vasudeva, it would be appropriate to first discuss Dynamic Systems Theory and consider individual and society as a system. The concept of chaos is taken from the field of mathematics that studies System. Oxford Dictionary defines system as "a set of things working together as parts of a mechanism or an interconnecting network; a complex whole"[5]. While chaos initially may mean confusion but as will be inferred it is a kind of order that is difficult to perceive as such. Here the three novels are also explored through the application of the nonlinear dynamics theory and the discussion on the chaotic attractors of dynamical systems. The complexity theorists view all systems as self-organizing.

Dynamical Systems Theory and Chaos Theory deal in the long-term qualitative behavior of dynamical systems. The study reveals that Systems that are stable in relation to their environment can become unstable and vice versa. This theory basically studies continuous state, deterministic systems. It includes both discrete and continuous time systems as well as linear and nonlinear systems. Dynamic Systems Theory was originally developed for applications to the problems arising in physics and engineering, but complex social systems can also be well explored through the application of the Chaos Theory or as also referred to as nonlinear dynamics, dynamical systems theory, or dynamical systems method by the mathematicians. Sometimes dynamic systems may exhibit aperiodic behavior and the linearity or cyclity is affected. This effect, that may occur due to just a minor change in the system may lead to major changes in future states of the system. Edward Lorenz while working through computer on the weather pattern observed that in dynamical systems even rounding numbers, that may be regarded as an insignificant change causes significant changes in results. This effect that triggers large changes on future results is termed as the butterfly effect. The world we live in, does not comprise mere objects but rather is made up of network of living and non-living complex systems. The components of the system are in continuous interacting relationships. Oxford Dictionary defines chaos as "the property of a complex system whose behavior is so unpredictable as to appear random, owing to great sensitivity to small changes in conditions." and" complete disorder and confusion" or "mayhem"[6]. According to Edward Lorenz (1993) chaos is a system "that is sensitively dependent on interior changes in initial conditions within one and the same system"[7].

The Oxford Dictionary defines order as "the arrangement or disposition of people or things in relation to each other according to a particular sequence, pattern or method' and "a state in which everything is in its correct or appropriate place" or "the state that exists when people obey laws, rules or authority".[8] Thus chaos and order seem to stand poles apart. In social systems also, order and chaos are often conceived of as polarized twin concepts, order referring to permanence, chaos to the opposite. The relationship between the two concepts is, however, more complicated. "Order," for instance, does not necessarily indicate absence of chaos. In society, though the systems show a cyclical pattern-the formation, dissolution, and reformation of order, yet it is observed widely that the pattern never repeats itself completely. The social life in one cycle is never an exact replica of the previous one. Determinism is the philosophical belief that every event or action is the inevitable result of preceding events and actions. Thus, in principle at least, every event or action can be completely predicted in advance or in retrospect. In thermodynamics, energy transfer is studied in three types of systems: isolated, closed and open ones. An isolated system is one that does not allow any exchange of energy or matter while closed system may exchange energy but not matter with an outside system. Open systems can exchange both matter and energy with an outside system.

\section{Section 3.2}

Since the three novels, The Immortals of Meluha, The Secret of the Nagas and The Oath of Vayuputras thematise chaos theory, it may lead to an assumption that the narrative is about fractured time, lost meanings and the absurdity of human condition, but the writer, Amish Tripathi has created a narrative in which the chaos theory symbolizes precisely the ways in which human beings can gain knowledge of the world and make knowledge meaningful in their particular human context. The structure of the novels is built around the juxtaposition of or interrelationship between two worlds of Suryavanshis and Chandravanshis. The first novel is set in Meluha and Ayodhya, capital of Swadeep, while its sequel takes the readers to Kashi, Magadh, Brangaridai and Dandak forests. The kingdom of Suryavanshis is Meluha and that of Chandravanshis is Swadeep. Meluha runs along the lines of RamRajya and strictly follows the Laws of Lord Rama. The Suryavanshi motto is 'Satya, Dharma, Maan'. Devagiri, the capital of Meluha is described as:

the city was divided into a grid of square blocks by the paved streets. There were 
footpaths on the side for pedestrian.... all the buildings were constructed as standard two storied block structures made of baked bricks......All windows and doors were built strictly on the side walls of buildings, never facing the main road.....The most common backgound colour though, appeared to be blue....the city was divided into many districts... Each district had its own markets, commercial and residential areas ${ }^{14}$.

The Chandravanshi motto is 'Shringar. Saundarya. Swatantrata.' Their capital Ayodhya is described in words:

Some open grounds had been converted into giant slums... The already narrow roads had been made richer home owning class and the poor landless who lived in slums. The Emperor had legalised all encroachments established before 1910 BC. That meant that slum dwellers could not be removed unless the government created alternate accommodation ${ }^{15}$.

'Here each house had its own individual allure. The Swadweepans... created houses that were expressions of passion and elegance. The Swadweepans had none of the restraints of the Meluhans. Everything was painted bright ${ }^{16}$.

In the most ordered city of Meluha, children are also brought up in most disciplined fashion:

all children that are born in Meluha are compulsorily adopted by the empire. All pregnant women have to travel there (Maika) for their delivery.... Once the child is born, he or she is kept in Maika for a few weeks for health reasons while the mother travels back to her own city.'...'The child is then put into the Meluha gurukul... They grow up with all the resources of the empire available to them... When the children turn sixteen, they are allocated to the applicant parents... ${ }^{17}$
Freedom for citizens is severely limited with social laws rigidly maintained by ideological means and force. Parent-child bonds are deliberately eroded with the child estranged from mother and its identity diluted soon after its birth. Healthy children are transferred to Maika, while the deformed and disabled ones deported from the kingdom and thus ideal society maintained and prided upon. Some Meluhans however 'tired of the regimented life' have taken refuge in Kashi, 'They tolerated the chaos of the Chandravanshi ways for the pleasure of watching their children grow ${ }^{18}$. Melhuan society can be placed within the modernist paradigm considering its reliance on totalizing theory. At the center, a logos is said to be at play; as in Daksha's forces of rationalization and Parvateshwar's adherence to Laws of Lord Rama. Thus the grandnarrative of Meluha is replete with assumptions of homogeneity, desirability of consensus and order. Daksha rests his views on some kind of conception of tension-reduction as the operative force in social structural development. The deformed are deployed out of kingdom. The diseased and handicapped are segregated from the mainstream society. Order is seen as desirable without further explanation. Deviance is defined in terms of distance from assumed acceptable standard of normativity.

The liberal Chandravanshi life is described as:

The people were living embodiments of the Chandravanshi way of life. The women wore skimpy clothes, brazen and confident about their sexuality,. The men were as fashion conscious as their women- what Meluhans would call dandies. the relationship between the men and women could only be characterized as one teetering on extremes. Extreme love coexisting with extreme hate, expressed with extreme loudness, all built on the foundations of extreme passion ${ }^{19}$.

Suryavanshis regard Chandravanshis as corrupt people:

'Yes,' said Daksha. 'The Chandravanshis are corrupt and disgusting people. No morals. No ethics. They are the source of all our problems. Some of us believe that Lord Ram was too kind. He should have completely destroyed them. But he forgave them and let them live. In fact, we have to face the mortification of seeing the Chandravanshis rule over Lord Ram's birthplace-Ayodhya!' ${ }^{20}$

\footnotetext{
14 Tripathi, Amish. The Immortals of Meluha.(2010) p.62-63. 15 Tripathi, Amish. The Immortals of Meluha.(2010) p.372. 16 Tripathi, Amish. The Immortals of Meluha.(2010) p.373. 17 Tripathi, Amish. The Immortals of Meluha.(2010) p.97.
}

18 Tripathi, Amish. The Secret of The Nagas. (2011) p.77.

19 Tripathi, Amish. The Immortals of Meluha.(2010) p.374

20 Tripathi, Amish. The Immortals of Meluha.(2010) p.100 
Further, in Book 2, Daksha continues "The evil Chandravandravanshi way of life has to end and these people have to be brought to our pure Suryavanshi ways" 21 . Handicapped people and mothers of still born, in Meluha are vikarmas. Apart from vikarmas, Meluhans are segregated into four categories: Brahmins, Kshatriyas, Vaishya and Shudras. Only royal class are allowed to keep track of their biological child brought up in Meluha. Meluha is beset by desperately low fertility rates following strict rules prohibiting mothers from reaching out to her child, almost immediately after birth. As a result, privileged return to their parents after education while the rest, according to their talents and knowledge are allotted parents of particular class. The patriarchal order of Meluhan society manages to keep broadly under control practices, such as caste discrimination and violence. However, soon readers realize that Daksha has been faced with the false choice of accepting and implementing such a social structure, for it is a form of totalitarianism. Chapter 2 of Book I, 'Land of Pure Life', reveals the anxiety of king Daksha, as his kingdom that so far seemed impenetrable and safe haven for its citizens is under threat by treacherous Chandravanshis. Apart from the occasional attacks, the kingdom figures as a model of empiricism and order. The entire kingdom, in fact looks like a microcosm of the universe with all in perfect order. However this rationality and empiricism soon seems to be destabilized.

\section{Section 3.3}

Limitations of the so called Daksha'a perfect society may be explained through Einstein's relativity theory. According to the theory, the existence of matter and its activity cannot be separated. Matter is made of molecules and atoms which further consist of subatomic particles, which in turn are energy bundles. At high speed these particles can be described adequately in the framework of the quantum theory. Swadeepan society which initially seems to be critique of Meluha, has found grounding in the insights of chaos theory and Lacanian thought. They privilege disorder rather than order. Their starting point is paralogism: privileging instabilities [9]. This model of society begins with far-from-equilibrium conditions as being the more "natural" state, and places a premium on flux, nonlinear change, chance, spontaneity, intensity, indeterminacy, irony, and orderly disorder. No permanent stable order is possible or even desirable. No center or foundation exists. They consider the search for an overall, all-encompassing totalizing theory as an illusory exercise. The appropriated modified discourse on the Chaos theory can be applied to the examination of the novels. Kellert defines chaos theory as "the qualitative study of unstable aperiodic behaviour in deterministic nonlinear dynamical systems"[10]. A determinist linear thinking of Suryavanshis over-simplifies reality. Their life and its working is as predictable as the

21 Tripathi, Amish. The Secret of the Nagas.(2011) p.13. movement of pendulum, a simple example of a dynamical system. Dynamical systems theory is the branch of mathematics devoted to the motions of systems which evolves according to simple rules. Man as well as society, as a system are complex in nature and thus cannot be studied as an isolated system. An isolated system, in physics is one where there can be no exchange of matter or energy. Every complex system is also a dissipative structure, as explained by Prigogine [11], as it takes on and dissipates energy as it interacts with its environment. Man constantly interacts with his ever-changing environment. Thought processes are generally non-deterministic in nature more like a maze, but the Meluhan rules do not realize that disorder, confusion, uncertainty, or instability prevails all the time. This is "the butterfly effect", a term used in Chaos theory to explain how a minor change may cause drastic and unexpected results. Each Meluhan who seems to be so stable in relation to his/her environment on deeper inspection seems to contain seeds of chaos and suppress the unstable in him. The forced orderliness of Meluhans is seen in their Maika and vikarma system. On the other hand Swadeepans' life appears to be chaotic at the surface but there exists some kind of order within their inner self.

\section{Section 3.4}

In Hindu mythology, while Sati or Parvati represents marriage and motherhood, Kali stands for destruction. She is also the one who protects and sacrifices for her children (devotees). Shiva's destruction opens the path for the new creation. In the selected texts, before meeting Shiva, Sati has no identity of her own. Her identity, nature and actions are defined and acted out vis-a-vis her father, Daksha. Much doting father but equally manipulative, king Daksha keeps Sati ignorant of the truth that she has given birth to deformed son and misinforms her of still born birth. Shiva succeeds in luring her into remarriage and thus into the wider circle of worldly life. In, Book two, however, it is Sati who introduces Shiva to Kali and thus extends his circle of activity. At this point, Shiva involves in the act of destruction/ creation which is actually an act of arranging and producing order from chaos. In Chapter 16 of Book 2 The Opposites Attract, Shiva embraces Parashuram, Sati unites with Kali and celibate Meluhan General Parvateshwar accepts the instigator of desire, seductive princess, Anandmayi. This union of opposites leads them to the state of chaos that self-organises and thus becomes the ideal basis for creativity. Such "attractors" of disorder, in the theory of chaos are equations that predict the long-term behaviour of complex systems. Just as butterfly flapping its wings causes a hurricane in another part of the world so are the lives of Shiva, Sati and Parvateshwar affected by the entry of these 'strange attractors' also termed as 'the butterfly effect'. Kali, who as Naga Queen seemed quite angry and erratic earlier, finally succeeds in bringing Shiva to the wilds of Dandaka Forests. Sati, the most obedient daughter, produces Kali before Daksha and in this way exposes the king's conspiracy. 
Parashuram, as an strange attractor leads Shiva to Brihaspati in Panchvati. Ganesh in Hindu mythology is the son of Shiva and Parvati. He is known to remove obstacles from the path of devotees. In the novel, Ganesh is Lord of the people. He strongly draws Shiva towards himself in an attempt to abduct Sati and thus is the most important 'strange attractor'. The entire plot in the novel is the outcome of Ganesh's actions. The Lord of the People and the turbulent conditions that create him, draws ordered complex systems into disorder. The state of non-equilibrium of the system is exposed by Ganesh and this non-equilibrium sets out in turn to reveal hidden potential concealed by equilibrium. In chaos theory, in a system multiple agents interact to generate strange attractors. Complexity approach to chaos believes in a tight relation between chaos and order. This interaction leads one to another in a dynamic process. Chaos, in this approach, is not avoided but utilized to organise the system, through an "attractor". Shiva's uncle tells him, My child, your destiny is much larger than these mountains. But in order to realise it, you will have to cross these very same massive mountains $^{22}$. The application of chaos theory to the study of these novels discusses the existence of multiple variables in a society that prevents predictability. Contrary to modernist Meluhans, Swadeepans as postmodernists consider ongoing flux and continuous change as desirable.

\section{Section 3.5}

Though the nation had been ruled by several competing kingdoms, Shiva bound them all. Meluha was ruled by Daksha, Ayodhya by King Dilipa. Chandraketu ruled over Branga and Athithigva over Benaras. Kali was the queen of Nagas and so on. Man's physical love for himself is perceived as an urge for self-preservation. This often le ads to savagery and barbaric actions. However his rational self-love makes him humane and compassionate. He compares his own social circumstances with others and is inspired to make the world worth living and work towards the progress of humanity. Irrational self love brings in vices of culture such as envy, ingratitude and sadistic pleasures. Meluhan society has advanced to such an extent that it now considers the human being solely intellectually or rationally and thus respects the moral laws of Lord Ram which in their society are strictly prescriptive as opposed to Swadeepan society which holds its descriptive perspective. As reflected to Shiva, when he meets a beggar at the temple. Swadeepans carry the motto of 'Passion. Beauty. Freedom ${ }^{23}$. On temple steps of Ayodhya, Shiva meets a beggar in torn clothes who offers a share of his food on a banana leaf. As Shiva is coaxed into eating with him:

Shiva could not find the heart to look up anymore. As his heart sank deeper and his tears rose, he ate the portion the old

22 Tripathi, Amish. The Secret of the Nagas .(2011) p.145.

23 Tripathi, Amish. The Immortals of Meluha .(2010) p.371. man gave him quickly. The food was over in no time.

Freedom. Freedom for the wretched to also have dignity. Something impossible in Meluha's system of governance $^{24}(\mathrm{IM}, 386$ italicized in the text).

Meluhan life is limited to a single culture and locality. The rest of the world is known dimly, if at all, and only then through the distorting filter of their own local society. Models of one-directional change assume that change in a certain direction induces further change in the same direction; models of curvilinear or cyclical change, on the other hand, assume that change in a certain direction creates the conditions for change in another direction. More specifically, it is often assumed that growth has its limits and that in approaching these limits the change curve will inevitably be bent, but the human race, as a whole, is a true dynamical system that follows the principles of chaos theory. Swadweep is 'a confederacy of aligned kings' ${ }^{25}$, where each king pays tribute to the Swadeepan Emperor and rules independently. In a debate with Dilipa, the Swadeepan Emperor concerning rights to subjects, Daksha states, "Then there will be chaos, ${ }^{126}$ Kashi has given refuge to Brangas. This is the place open to all kinds of social, cultural and commercial transactions. Many Meluhans have fled to this city. Brangaridai has Nagas as their allies.

\section{Conclusion}

In this age of demythologization, Amish firmly establishes a fictionalized historical account affirming that dwelling in geography of India imbues people with salvific strength. The fictionist seems to hold that human beings have an active intellect but a passive sensibility. On the other hand, Brahma has intuitive intellect, that creates its own matter. Shiva, however excels other humans in knowing the sensory data as they are in themselves rather than an average man who entangled in crudities of life, perceives the manifold brought under the form of space and time. Amish portrays the world of Meluha, Swadweep et al in Shiva Trilogy as a relative existence. Its existence is dependent on Brahma. In Advaita Vedanta, only Brahma is real. Existence and immutability are the parameters of Reality. Brahma is pure Consciousness. According to the Upanishads, Brahma is existence, Consciousness and endless. This renders Brahma, characteristic of immutability. Indian philosophy believes Brahma to be the only Reality, the absolute existence. Meluhans, in fact still live in an illusory world of lord Ram as after several mutations the later has actually ceased to exist.

24 Tripathi, Amish. The Immortals of Meluha .(2010) p.386.

25 Tripathi, Amish. The Secret of the Nagas .(2011) p.15

26 Tripathi, Amish. The Secret of the Nagas .(2011) p.15 
Ram Rajya had a set of codes which have undergone changes as per convenience of the mighty without the rulers or ruled ever realizing the change. Amish as a free thinker, tries to explain natural phenomenon with the help of natural causes. Though scientific in spirit, his work has an strong undercurrent of faith in Indian life and thought. He maintains that man in his pristine existence was glorious but now in this world is in fallen state. Amish's method of philosophizing seems to be of great relevance in the present world of restlessness and unease. Initially it seems that the author employs mathematical method of philosophy with a view to obtain certitude in knowledge. He refuses to believe in preconceived notions. He begins with something vague and indefinite and later on step by step attains clarity and distinctness. Meluhan's specific values of culture could sustain life for their kingdom alone. Cultural values are essential to preservation of life. Meluhan culture and tradition stoop to work against Natural Law leading to war by Neelkanth. Culture and tradition are strengthened through the enlivenment of Natural Law. Shiva understands the culture of Meluha and this knowledge helps him to facilitate communication with Suryavanshis. With an intercultural approach that involves not only knowing about another culture but also attempting to understand how one's own culture shapes perceptions of oneself, of the world, and of our relationship with others he engages in uprooting the Evil from the life of people.

The agency of culture ought to refine human element. Society should work towards producing enlightened individuals who do not violate laws of nature. Laws of Lord Ram are Laws of Nature. They are responsible for creation and evolution of life, but the present Meluhan royalty distorts them to suit its convenience leading to loss of values and destruction. Cultural values of Meluha have helped Meluhan evolve in the reign of Brahmnayak, Daksha's father.

In this way, Amish's philosophy differs from the Western one where culture implies "customary knowledge" regardless of universal laws that govern geography and culture. Meluhans while too engrossed in geographic and climatic conditions that support the Laws of Nature ignore the unmanifest field of pure consciousness and construct man-made laws of their states at the cost of Laws of Nature. The Trilogy can be viewed as an attempt to revive the culture and tradition of India by bringing to the centre of thinking, the Laws of Nature. Rigveda has been identified as an earliest philosophical text of India. The text speculates about 'the unity and ultimate ground of the world'. [12] Rivers in Indian subcontinent have being regarded as the sites of sacred power. Amish through his imaginative faculty establishes historically how the given sites became popular as sacred places. The temples and pithas simply serve to mark, specify and objectify, the sacredness in every region, wherever Shiva travelled. This gives cultural and historical unity to the nation

Shiva, the hero of the novel undergoes archetypal-imaginative journey of transformation. The hero in the novel does not fight the villain but the writer elevates the action in his fiction, as the task of Shiva is not to trounce evil individual but to confront the evil that attaches man to itself. Shiva and Sati who set out on their journey, reach the stage of maturation in Swadweep when they confront the cultural other. They gain self-control in Kashi and then set out in search of answer to the mystery of Truth versus deception/ Perception versus reality. Advaita Vedanta accepts the pluralistic nature of the world. It is neither monism nor non-dualism. It believes Reality to be Pure Consciousness. All the diverse areas in the empirical universe are connected at the deeper level. Pure Shiva is capable of seeing into the real nature of things, while others are lost in what they appear to be. This paper is based on the premise that in Shiva's inaction lies his action. To live is to act.

\section{REFERENCES}

[1] Derrida,J. Differance. In M. Taylor (Ed) Deconstruction in Context: Literature and Philosophy [396-420]. Chicago: Univ. of Chicago Press. 1986.

[2] Jung, Carl. On the Nature of Dreams. The Structure and Dynamics of the Psyche. Vol. 8 of Collected Works. Ed. Herbert Read. London: Routledge and Kegan Paul, 1953-1978. p. 505.

[3] Jung, Carl. On the Nature of Dreams. The Structure and Dynamics of the Psyche. Vol.16 of Collected Works. Ed. Herbert Read. London: Routledge and Kegan Paul, 1953-1978. p. 352.

[4] Jung, C. G. The Red Book , Sonu Shamdasani (Editor, Translator), W. W. Norton \& Company; 1st edition. New York. 2009. p. 301.

[5] Hornby, Turnbull ed. Oxford Advanced Learner's Dictionary, O U P. 1996. p. 1212.

[6] Soanes, Spooner, Hawker.(Ed.) The Oxford Thesaurus of English Delhi: OUP, N.Delhi. 2009. p. 137.

[7] Lorenz, E. The Essence of Chaos. Seattle WA.: University of Washington Press. 1993. p. 24.

[8] Oxford English Dictionary. USA: Oxford University Press. 1989. p. 816 .

[9] Lyotard, J-F. The Postmodern Condition: A Report on Knowledge. Minneapolis: Univ. of Minnesota Press. 1988.

[10] Kellert, S.H. In the Wake of Chaos: Unpredictable Order in Dynamical Systems. Chicago: The University of Chicago Press. 1993. p. 2.

[11] Nicolis G.,Prigogine, I. Exploring Complexity: An Introduction. New York: W.H. Freeman and Co. 1989.

[12] Coward, H. Derrida and Indian Philosophy. Albany, New York: State Univ. of New York Press. 1990. p. 5.

[13] Hegel, G.W. Lectures on the Philosophy of World History. New York: Cambridge University Press. 1995.

[14] McHale, Brian. Postmodernist Fiction. New York: Methuen. 
1987.

[15] Muller, F.M. (Ed.) The Satapatha Brahmana. New Delhi: Motilal BanarsiDass Publishers. 1982.

[16] Panda,NC. Maya in Physics. New Delhi: Motilal BanarsiDass Publishers. 1996.

[17] Pandit, S. An Approach to the Indian Theory of Art and Aesthetics. New Delhi: Sterling. 1997.

[18] Tripathi, Amish. The Immortals of Meluha. Chennai: Westland Ltd. 2010.Print. 2010.

[19] The Secret of Nagas. Chennai: Westland Ltd. 2011.

[20] The Oath of the Vayuputras Chennai: Westland Ltd. 2013. 